\title{
Separation of Argon and Oxygen by Adsorption on a Titanosilicate Molecular Sieve
}

\author{
$\underline{\text { A. Ansón }}^{1}$, S.M. Kuznicki ${ }^{2}$, T. Haastrup ${ }^{2}$, T. Kuznicki ${ }^{2}$, C.C.H. Lin $^{2}$, G. Konya ${ }^{3}$, B.C. Dunn ${ }^{3}$, \\ E.M. Eyring ${ }^{3}$, D.B. Hunter ${ }^{4}$ \\ ${ }^{1}$ Instituto de Carboquímica, CSIC, Miguel Luesma Castán 4, 50018 Zaragoza, Spain \\ ${ }^{2}$ Department of Chemical and Materials Engineering, University of Alberta, Edmonton, AB \\ T6G 2G6, Canada \\ ${ }^{3}$ Department of Chemistry, University of Utah, Salt Lake City, UT 84112, USA \\ ${ }^{4}$ Savannah River National Laboratory, Aiken, SC 29808, USA \\ alanson@icb.csic.es
}

The separation of argon and oxygen is one of the important processes in the industrial purification of the constituents of air, and is also one of the most difficult. The basic methods used to effect this separation include cryogenic distillation and selective adsorption.

Several titanosilicates, including ETS-4 [1], ETS-10 [2], and other structures based on octahedral titanium units [3], have been recognized for their adsorptive and molecular sieving properties. ETS-4, in particular, has been noted for its ability to differentiate molecules by size, including the commercial separation of $\mathrm{N}_{2}$ from methane at high pressure.

In the present communication, we examine the separation of $\mathrm{O}_{2}$ and $\mathrm{Ar}$ at room temperature using Ba-RPZ, a new synthetic titanosilicate molecular sieve. RPZ is synthesized by mixing sodium silicate, $\mathrm{NaOH}$ and $\mathrm{TiCl}_{3}$ with potassium chloride. From X-ray powder diffraction analysis, it is clear that, like ETS-4 [4], RPZ (Reduced Pore Zorite) is structurally related to the mineral zorite [5].

A clean resolution of $\mathrm{O}_{2}$ and Ar was achieved in pulse chromatographic experiments using Ba-RPZ standard columns (0.25” OD, 3.5 grams of adsorbent), even when the argon content was only $10 \%$ of the mixture (Figure 1). The argon and oxygen retention times were almost identical regardless of the composition of the $\mathrm{O}_{2}$-Ar mixture. In another experiment, using a column containing 30 grams of adsorbent and a continuous $\mathrm{O}_{2}+\mathrm{Ar}$ feed at $10 \mathrm{~cm}^{3} / \mathrm{min}$, argon breakthrough was detected more than 5 minutes before oxygen breakthrough, even in the case of mixtures with low argon content $\left(95 \% \mathrm{O}_{2}\right)$.

Equilibrium adsorption isotherms and isosteric heats of adsorption for oxygen and argon were found to be almost identical at room temperature. The thermodynamic selectivity was found to be mildly in favor of oxygen $(\sim 1.1-1.2)$. However, the adsorption of oxygen was observed to be much faster than argon (Figure 2), indicating that the separation of the $\mathrm{O}_{2}+\mathrm{Ar}$ mixtures was based on the sieving properties of the adsorbent and the difference in sizes of $\mathrm{O}_{2}$ molecules and Ar atoms. This indicates that a suitably oriented oxygen is physically smaller than argon, despite the fact that many references assume oxygen is larger than argon.

\section{References:}

[1] S.M. Kuznicki, V.A. Bell, S. Nair, H.W. Hillhouse, R.M. Jacubinas, C.M. Braunbarth, B.H. Toby, M. Tsapatsis, Nature, 412 (2001) 720.

[2] S.M. Kuznicki, US Patent 5,011,591 (1991).

[3] V. Sebastián, Z. Lin, J. Rocha, C. Téllez, J. Santamaría, J. Coronas, Chem. Mater., 18 (2006) 2472.

[4] S.M. Kuznicki, U.S. Patent 4,938,939 (1990).

[5] G. Cruciani, P. De Luca, A. Nastro, P. Pattison, Micropor. Mesopor. Mater., 21 (1998) 143. 


\section{Figures:}

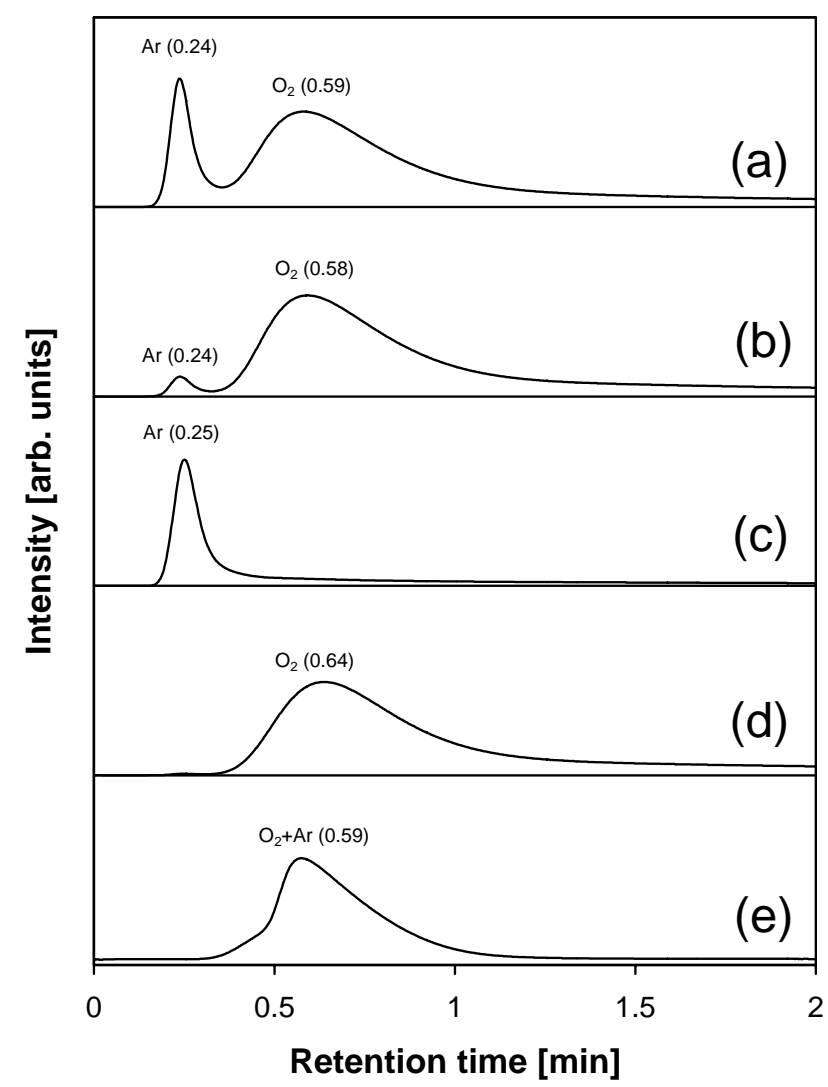

Figure 1. Chromatographic profiles at $30^{\circ} \mathrm{C}$ under $30 \mathrm{~cm}^{3} / \mathrm{min}$ carrier gas helium obtained by injecting: a) $50-50 \% \mathrm{O}_{2}-\mathrm{Ar}$; b) $90-10 \% \mathrm{O}_{2}-\mathrm{Ar}$; c) pure argon; d) pure oxygen in a column of Ba-RPZ, and e) $50-50 \% \mathrm{O}_{2}$-Ar in a column of Ba-ETS-4.

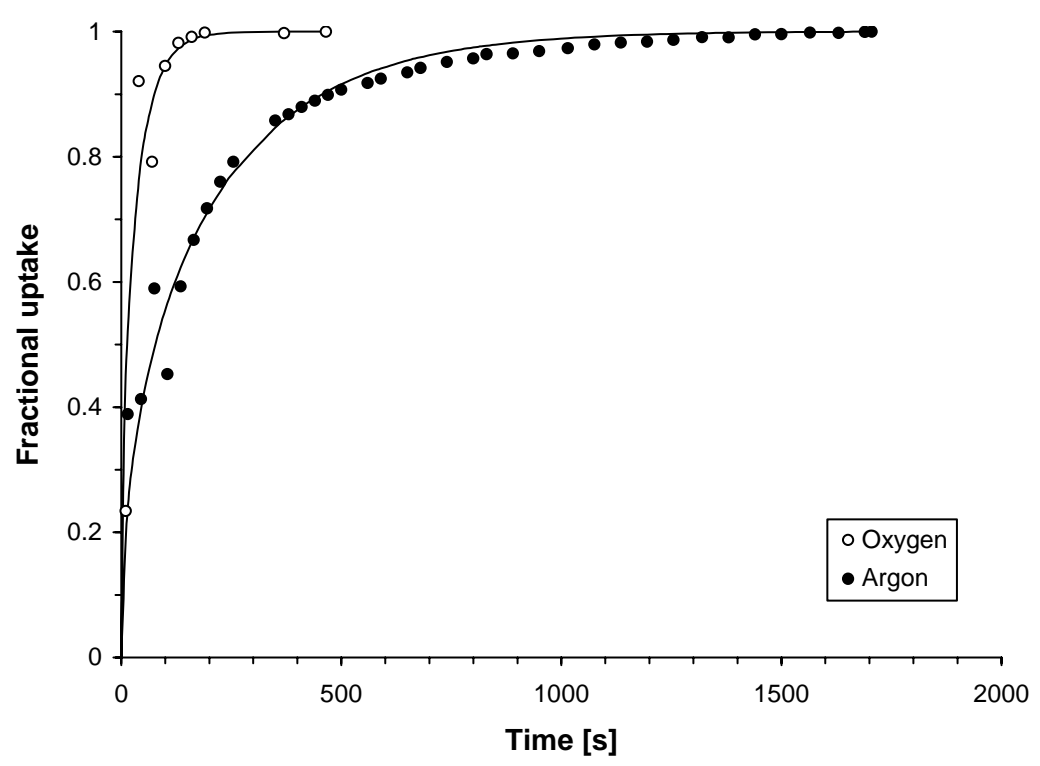

Figure 2. Adsorption uptake curves for oxygen and argon on Ba-RPZ at $30^{\circ} \mathrm{C}$ in the pressure step 70-100 kPa. 